\title{
LAPAROSKOPI PADA PASIEN KISTA OVARIUM PERMAGNA DENGAN ANESTESI SPINAL
}

\author{
Dwi Lunarta Docterina Sutanti Siahaan
}

Departemen Anaestesi, Fakultas Kedokteran, Universitas Methodist Indonesia, Medan, Indonesia Email: rinasiahaan72@gmail.com

DOI: https://doi.org/10.46880/methoda.Vol11No2.pp149-155

\begin{abstract}
Ovarian cysts is one of the most common gynaecology benign tumour found in women in their reproductive years. Ovarian cysts consist of fluid-filled pockets such as water-filled balloons in the ovaries. Permagna ovarian cyst is a cyst with a diameter exceeding $10 \mathrm{~cm}$. Clinical manifestations that occur can include abdominal discomfort, difficulty urinating, pelvic pain, and pain during intercourse and menstrual disorders. Medical management that can be performed in patients with ovarian cysts is by hormonal and surgical treatment. Through surgery, management of ovarian cysts can be done with laparotomy or laparoscopy. Laparoscopy surgery of ovarian cysts requires anesthesia. It is known that laparoscopy procedures are usually performed under general anesthesia due to respiratory changes caused by pneumoperitoneum. However, the use of spinal anesthesia has emerged as an alternative for laparoscopy because of its safe use. Anesthesia management was reported in 22 years old patient with Permagna Ovarian Cyst who performed laparoscopic surgery. Anesthesia technique with spinal anesthesia using bupivacaine hcl 0.5\% $20 \mathrm{mg}$ added pethidine $25 \mathrm{mg}$. During operation, patient was sedated with midazolam 2.5-5 mg intravenous, hemodynamic was stable and patient also comfortable until operation finished.
\end{abstract}

Keyword: Permagna Ovarian Cyst, Laparoscopy, Spinal Anesthesia.

\begin{abstract}
ABSTRAK
Kista ovarium merupakan salah satu tumor jinak ginekologi yang paling sering dijumpai pada wanita di masa reproduksinya. Kista ovarium terdiri dari kantong berisi cairan seperti balon berisi air yang terdapat di ovarium. Kista ovarium permagna merupakan kista dengan diameter melebihi $10 \mathrm{~cm}$. Manifestasi klinis yang terjadi dapat berupa ketidaknyamanan pada abdomen, sulit buang air kecil, nyeri panggul, dan nyeri saat senggama serta gangguan menstruasi. Penatalaksanaan medis yang dapat dilakukan pada pasien dengan kista ovarium adalah dengan pemberian obat hormonal dan pembedahan. Melalui pembedahan, penatalaksanaan pada kista ovarium dapat dilakukan dengan laparotomi atau laparoskopi. Salah satu penanganan kista ovarium yaitu dengan operasi laparoskopi yang membutuhkan suatu pembiusan. Diketahui bahwa prosedur laparoskopi biasanya dilakukan dengan anestesi umum karena perubahan pernafasan yang disebabkan oleh pneumoperitoneum. Namun, penggunaan anestesi spinal telah muncul sebagai alternatif pilihan untuk laparoskopi oleh karena keamanan penggunaannya. Dilaporkan penatalaksanaan anestesi pada pasien usia 22 tahun dengan Kista Ovarium Permagna yang dilakukan operasi laparoskopi. Teknik anestesi dengan anestesi spinal dengan menggunakan bupivacaine hcl $0.5 \% 20 \mathrm{mg}$ ditambahkan petidin $25 \mathrm{mg}$. Selama operasi pasien diberikan sedasi dengan midazolam 2,5- $5 \mathrm{mg} / \mathrm{iv}$, hemodinamik stabil dan pasien dalam keadaan nyaman hingga selesai operasi.

Kata Kunci: Kista Ovarium Permagna, Laparoskopi, Anestesi Spinal.
\end{abstract}




\section{PENDAHULUAN}

Kista ovarium adalah suatu penyakit ganguan organ reproduksi wanita. Kista ovarium merupakan salah satu tumor jinak ginekologi yang paling sering dijumpai pada wanita di masa reproduksinya. Kista ovarium terdiri dari kantong berisi cairan seperti balon berisi air yang terdapat di ovarium. Kebanyakan kista ini jinak, sementara sebagian kecil lainnya bisa berupa kista yang ganas. Kista ovarium yang ganas disebut juga dengan kanker ovarium. Kista ovarium permagna merupakan kista dengan diameter melebihi $10 \mathrm{~cm}$. Namun, beberapa penulis lain mendefinisikan kista ovarium permagna saat mereka mencapai tingkat umbilikus dan sangat besar (Wiknjosastro, 2005).

Berdasarkan Survei Demografi Kesehatan Indonesia angka kejadian kista ovarium di Indonesia mencapai $37,2 \%$, dan paling sering terdapat pada wanita berusia antara 20-50 tahun dan jarang pada pubertas (Wiknjosastro, 2005).

Kista ovarium menimbulkan beragam manifestasi klinis. Manifestasi klinis yang terjadi dapat berupa ketidaknyamanan pada abdomen, sulit buang air kecil, nyeri panggul, dan nyeri saat senggama serta gangguan menstruasi. Adanya gangguan menstruasi ini menyebabkan Mishawaka berpendapat bahwa wanita yang mengalami kista ovarium akan mengalami kemandulan (infertilitas). Hal ini dapat menimbulkan kecemasan pada pasiennya (Depkes R.I, 2020).

Penatalaksanaan medis yang dapat dilakukan pada pasien dengan kista ovarium adalah dengan pemberian obat hormonal dan pembedahan. Melalui pembedahan, penatalaksanaan pada kista ovarium permagna dapat dilakukan dengan laparotomi atau laparoskopi (Hadibroto, 2005).

Dewasa ini pemakaian laparoskopi sering digunakan untuk mendiagnostik massa di adneksa maupun sebagai terapi operatif untuk mengangkat massa tersebut. Dibidang ginekologi laparoskopi sering digunakan untuk mengangkat kista di ovarium (Eltabbakh, 2016).

Laparoskopi operatif memerlukan tiga komponen dasar yaitu keterampilan, kelengkapan instrumen, fasilitas kamar operasi dan tim operasi yang terlatih. Keuntungannnya adalah perdarahan minimal, tingkat presisi operasi tinggi, komplikasi rendah, lama perawatan singkat dan luka operasi minimal. Dengan berkembangnya inovasi instrumen dan teknik operasi, indikasi laparoskopi operatif menjadi lebih luas (Eltabbakh, 2016).

Prosedur laparoskopi biasanya dilakukan dengan anestesi umum karena perubahan pernafasan yang disebabkan oleh pneumoperitoneum yaitu berkumpulnya udara di rongga perut, yang merupakan bagian integral dari laparoskopi. Kontrol ventilasi yang tepat pada terkendali pada anestesi umum merupakan prosedur yang ideal untuk laparoskopi (Eltabbakh, 2016).

Namun, baru-baru ini penggunaan anestesi regional telah muncul sebagai alternatif pilihan untuk laparoskopi. Berbagai laporan dalam literatur menunjukkan keamanan penggunaan anestesi spinal, epidural, dan gabungan dalam prosedur laparoskopi. Kelebihan anestesi regional dapat meliputi: pencegahan manipulasi jalan nafas, pasien bernafas spontan intraoperatif, mual dan muntah minimal, analgesia pascaoperasi yang efektif, dan ambulasi awal dan pemulihan. Namun, anestesi regional mungkin terkait dengan beberapa efek samping seperti kebutuhan blok sensorik yang lebih lebih tinggi, hipotensi yang lebih parah, ketidaknyamanan bahu akibat iritasi diafragma, dan gangguan pernafasan yang disebabkan oleh pneumoperitoneum (Moradan, 2015).

Terbentuknya pneumoperitoneum merupakan bagian integral dari prosedur laparoskopi dan biasanya dilakukan dengan insuflasi karbon dioksida untuk visualisasi abdomen. Efek utamanya adalah karena tekanan intra-abdomen yang meningkat yang menyebabkan berbagai perubahan pernapasan, kardiovaskular dan neurologis dan lainnya (Bajwa \& Kulshrestha, 2016).

\section{KARDIOVASKULAR}

Efek kardiovaskular terutama bergantung pada tekanan intra-abdomen dan penyerapan karbon dioksida ke dalam sirkulasi sistemik. Pada tekanan intra-abdomen yang lebih rendah 
kurang dari $15 \mathrm{mmHg}$, venous return diperbesar karena pengosongan pembuluh darah splenic, dan dengan demikian output jantung dan tekanan darah meningkat. Pada tekanan intra-abdomen yang lebih tinggi lebih dari $15 \mathrm{mmHg}$, karena kompresi vena cava inferior dan kolateral lainnya, venous return berkurang, sehingga mengurangi curah jantung dan tekanan darah. Berbagai bradiaritmia yang menyebabkan blok atrioventrikular dan cardiac arrest dapat terjadi karena stimulasi vagal pada pemasangan trocar, peritoneal stretch atau carbon dioxide embolization.

Prinsip terjadinya respon fisiologis ini adalah peningkatan resistensi vaskular sistemik (SVR), tekanan pengisian miokardium, bersama - sama dengan penurunan awal cardiac index (CI), dengan perubahan yang kecil dari frekuensi denyut jantung (HR). Karakteristik respon hemodinamik dijelaskan sebagai berikut: diawali dengan terjadinya penurunan cardiac index setelah insuflasi gas $\mathrm{CO}_{2}$ intra peritoneum dan selanjutnya diikuti dengan pemulihan. Joris dkk. menemukan penurunan yang signifikan dari cardiac index $(30-40 \%)$ setelah induksi anestesi dan posisi Trendelenburg (head-down position), selanjutnya terjadinya penurunan cardiac index sampai $50 \%$ setelah insuflasi intra peritoneum. Kembalinya cardiac index secara bertahap setelah terjadinya penurunan SVR. Fraksi ventrikel kiri menurun sesaat setelah insuflasi intraperitoneum dan kembali ke nilai awal setelah 30 menit pneumoperitoneum (Hadibroto, 2005).

\section{PERNAPASAN}

Insuflasi intraperitoneum oleh $\mathrm{CO}_{2}$ untuk membuat pneumoperitoneum pada laparoskopi, mengakibatkan perubahan pada ventilasi dan respirasi yang dapat menyebabkan 4 komplikasi respirasi: empisema subkutis $\mathrm{CO}_{2}$, pneumothoraks, intubasi endobronkial, dan emboli gas. Perubahan fungsi paru selama insuflasi abdomen meliputi penurunan volume paru, penurunan komplians paru, dan peningkatan tekanan puncak jalan nafas (peak airway pressure). Komplians paru menurun 30 $50 \%$ pada pasien sehat, obesitas, dan ASA III -
IV. Penurunan kapasitas residu fungsional (KRF) dan komplians paru yang berhubungan dengan posisi terlentang dan induksi anestesi yang selanjutnya diperberat oleh insuflasi $\mathrm{CO}_{2}$ dan perpindahan ke sefalad diafragma selama posisi Trendelenburg dan perubahan distribusi ventilasi dan perfusi paru yang disebabkan oleh peningkatan tekanan jalan nafas (airway pressure) (Hadibroto, 2005).

Hipoksemia oleh karena penurunan kapasitas residu fungsional pada pasien yang sehat sangat jarang selama laparoskopi. Penurunan oksigenasi arteri (hipoksemia) disebabkan penurunan KRF, atelektasis, gangguan ventilasi perfusi, dan pintasan intrapulmoner pada pasien obesitas dengan riwayat merokok yang lama atau pasien dengan penyakit paru.

Posisi Trendelenburg menyebabkan perpindahan organ viseral dan diafragma. KRF, volume total paru, dan komplians paru akan menurun, bahkan bisa berkembang menjadi atelektasis. Perubahan ini biasanya dapat ditoleransi dengan baik oleh pasien sehat, namun pada pasien obesitas, pasien tua, dan pasien dengan penyakit paru meningkatkan resiko hipoksemia. Posisi Trendelenburg cenderung menyebabkan pergeseran trakea ke atas, sehingga pipa endotrakea yang terfiksasi dimulut bisa bermigrasi kedalam bronkus utama kanan. Pergeseran trakeobronkial ini diperbesar oleh insuflasi abdomen (Bajwa \& Kulshrestha, 2016).

Kelarutan $\mathrm{CO}_{2}$ yang tinggi meningkatkan absorbsi sistemik oleh pembuluh darah peritoneum, ditambah dengan volume tidal yang lebih rendah karena rendahnya komplians paru menyebabkan peningkatan kadar $\mathrm{CO}_{2}$ arteri dan penurunan $\mathrm{pH}$. Peningkatan $\mathrm{PaCO}_{2}$ yang progresif mencapai kondisi konstan 15 - 30 menit setelah mulainya insuflasi $\mathrm{CO}_{2}$ pada pasien dengan kontrol ventilasi mekanik selama laparoskopi ginekologi dengan posisi trendelenburg atau laparoskopi kolesistektomi pada posisi head up. Peningkatan $\mathrm{PaCO}_{2}$ tergantung pada tekanan intra abdomen. Selama laparoskopi dengan anestesi lokal, $\mathrm{PaCO}_{2}$ tetap tidak berubah namun ventilasi semenit meningkat. Pada anestesi umum dengan nafas spontan kompensasi hiperventilasi tidak mencukupi untuk menghindari hiperkapnea 
karena anestesi menginduksi depresi ventilasi dan peningkatan kerja pernafasan yang disebabkan oleh penurunan komplian torakopulmonal. Oleh karena hal ini terjadi dalam waktu 15 - 30 menit untuk mencapai $\mathrm{PaCO}_{2}$ konstan, teknik anestesi dengan menggunakan nafas spontan harus dibatasi untuk prosedur operasi yang pendek pada tekanan intra abdomen yang rendah (Bajwa \& Kulshrestha, 2016).

\section{SISTEM GASTROINTESTINAL}

Pasien-pasien yang menjalani laparoskopi biasanya dianggap beresiko tinggi untuk terjadinya sindrom aspirasi asam lambung karena regurgitasi gaster akibat peningkatan tekanan intragastrik karena peningkatan tekanan intra abdominal. Namun, selama pneumoperitoneum, tonus sfingter esophagus inferior jauh lebih kuat daripada tekanan intragastrik dan peningkatan tekanan ini membatasi insidensi regurgitasi (Bajwa \& Kulshrestha, 2016).

\section{SIRKULASI MESENTERIK}

Pembuluh darah viseral adalah yang pertama mengalami kompresi pada peningkatan tekanan intra abdominal, sehingga mengakibatkan disfungsi organ karena kolapsnya pembuluh darah kapiler dan venavena kecil. Hiperkapnia akibat simpatotonia, kompresi mekanis organorgan abdominal, posisi Trendelenberg, dan pelepasan vasopresin adalah beberapa faktor yang turut mengakibatkan menurunnya aliran darah mesenterik (Bajwa \& Kulshrestha, 2016).

\section{SIRKULASI HEPATOPORTAL}

Peningkatan tekanan intra abdominal $(>20$ $\mathrm{mmHg}$ ) mengakibatkan peningkatan tahanan dan aliran balik pada pembuluh darah abdominal. Pelepasan hormon (katekolamin, angiotensin, dan vasopressin) selama pneumoperitoneum akan semakin meningkatkan tahanan vaskuler mesenterik sehingga mengakibatkan penurunan yang berarti pada volume darah hepatik dan splanknik. Tekanan intraabdominal $>20 \mathrm{mmHg}$ menyebabkan penurunan $60 \%$ pada aliran darah vena porta sehingga mengakibatkan disfungsi hepar, yang akan menetap lebih lama pada periode postoperative. Terdapat penurunan suplai darah secara menyeluruh ke semua organ (Bajwa \& Kulshrestha, 2016).

\section{FUNGSI GINJAL}

Peningkatan tekanan intraabdominal mempengaruhi hemodinamik ginjal melalui perubahan pada curah jantung dan efek langsung aliran darah ginjal. Obstruksi mekanis aliran darah vena renalis yang disertai peningkatan aktivitas simpatis, peningkatan ADH plasma dan peningkatan aktivitas reninangiotensin plasma akan meningkatkan resistensi vaskuler ginjal sehingga mengakibatkan penurunan tekanan filtrasi dan produksi urine (Bajwa \& Kulshrestha, 2016).

\section{TEKANAN INTRAKRANIAL DAN TEKANAN INTRAOKULER}

Peningkatan tekanan intra abdominal akan menekan vena cava inferior dan meningkatkan tekanan spinal lumbal dengan menurunkan drainase dari pleksus lumbalis, sehingga meningkatkan tekanan intrakranial dan intraokuler. Hiperkapnia menyebabkan refleks vasodilatasi pada sistem saraf pusat dan hal ini juga turut meningkatkan tekanan intrakranial (Bajwa \& Kulshrestha, 2016).

\section{METODOLOGI}

\section{Laporan Kasus}

Perempuan usia 22 tahun datang ke IGD rumah sakit pada tanggal 28 November 2017 dengan keluhan adanya benjolan pada perut setinggi pusar. Benjolan dirasakan sejak 1 tahun yang lalu dan semakin membesar, tidak ada riwayat mual muntah serta $\mathrm{BAB}$ dan BAK dalam batas normal.

Pada pemeriksaan fisik ditemukan pasien pucat (-), ikterik (-). Didapatkan hasil pemeriksaan tekanan darah 120/78 $\mathrm{mmHg}$, nadi $78 \mathrm{x} /$ menit, laju nafas $16 \mathrm{x} /$ menit dan suhu $36,7^{\circ} \mathrm{C}$. Konjungtiva tidak anemis dan sklera tidak ikterik. Pemeriksaan jantung tidak ditemukan kelainan dan pada pemeriksaan paru tidak ditemukan ronki maupun wheezing. Pada 
pemeriksaan abdomen ditemukan adanya benjolan di perut setinggi pusar, pinggir rata dan bisa digerakkan pada perabaan. Peneriksaan ekstremitas, didapati akral hangat, merah kering. Edema tidak dijumpai.

Pemeriksaan laboratorium menunjukkan: $\mathrm{Hb}$ 13,6 g/dl, leukosit $6640 / \mathrm{mm}^{3}$, LED $63 \mathrm{~mm} / \mathrm{jam}$, trombosit $267.000 / \mathrm{mm}^{3}$, hematocrit $37,7 \%$, eritosit 4,42 x 10\% $/ \mathrm{mm}^{3}, \mathrm{MCV} 85,2 \mathrm{fl}, \mathrm{MCH} 30,7$ pg, MCHC 36,1, hitung jenis 0,3/0.2/71,1/22,8/3,1. Pemeriksaan waktu pembekuan darah 4', waktu perdarahan 10'. Pemeriksaan kadar gula darah menunjukkan nilai $74 \mathrm{mg} / \mathrm{dl}$.

USG abdomen menunjukkan uterus besar biasa, tampak massa kistik, tidak terukur kaliber, massa sulit dinilai, kesimpulan kista ovarium permagna.

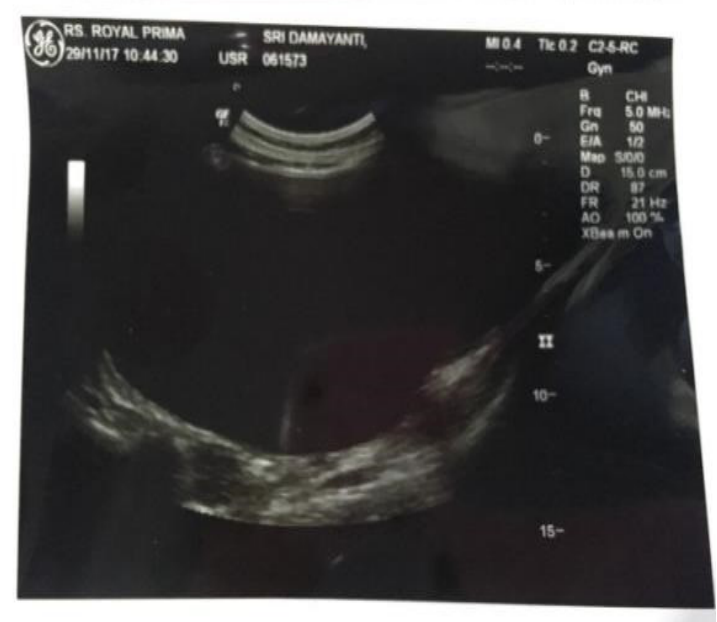

Gambar 1. USG Abdomen

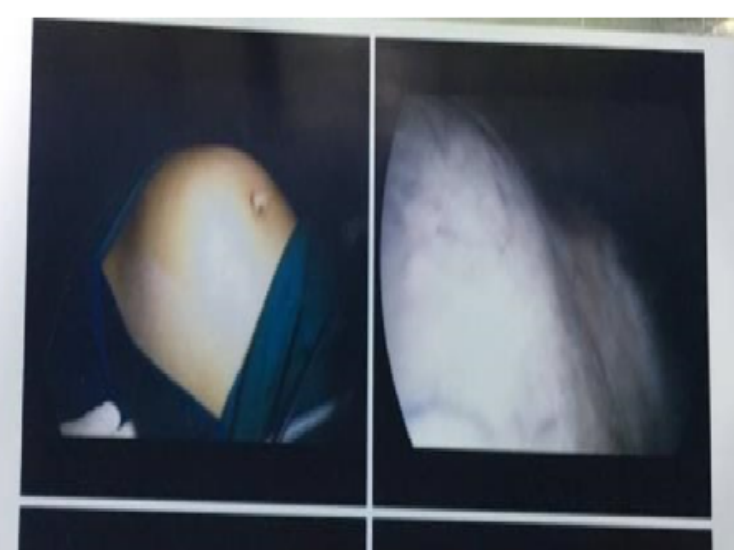

Gambar 2. Laparoskopi

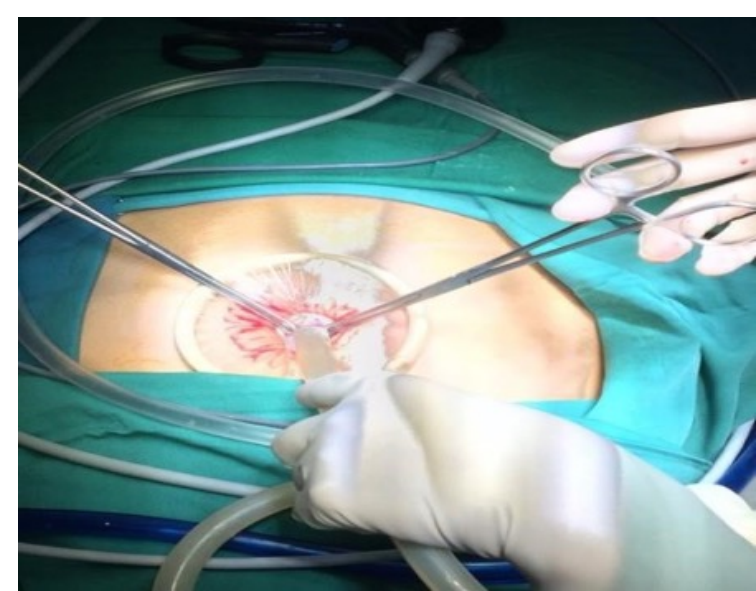

Gambar 3. Laparoskopi dengan Teknik Single Port

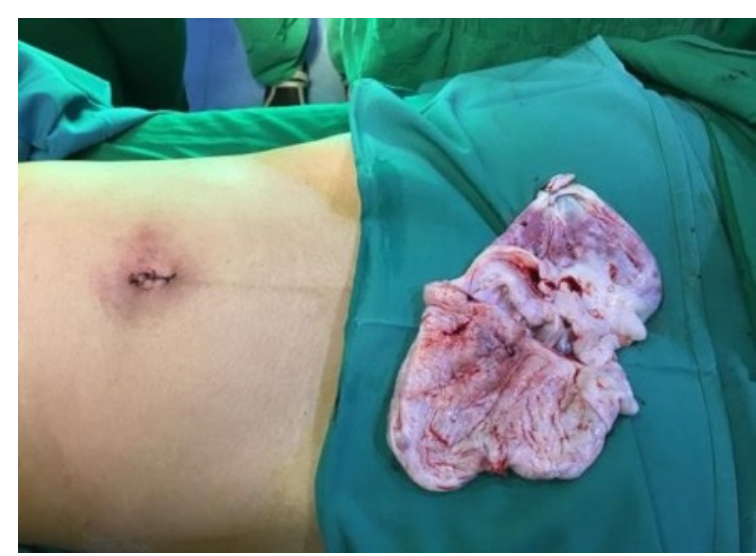

Gambar 4. Kapsul Kista (Post-op)

Sebelum dilakukan anestesi, pasien dipuasakan selama 8 jam dan dipasang infus. Kemudian diberikan cairan RL 1000 cc sebagai cairan preoperasi. Sebelumnya diberikan premedikasi injeksi ceftriaxone $1 \mathrm{~g}$ / iv. Setelah persiapan alat dan obat selesai, pasien dimasukkan kedalam kamar operasi. Di kamar operasi dipasang monitor EKG, pulse oxymetry. Tercatat tekanan darah $115 / 78 \mathrm{mmHg}$, frekuensi jantung $82 \mathrm{x} /$ menit, frekuensi nafas $16 \mathrm{x} / \mathrm{mnt}$. $\mathrm{SpO}_{2} 100 \%$. Kemudian dilakukan anestesi spinal dengan menggunakan bupivacaine hcl 0.5\% 20 mg ditambahkan petidin $25 \mathrm{mg}$. Pasien diposisikan Trendelenburg. Oksigen diberikan melalui kanul nasal 2 1/mnt.

Operasi berlangsung kurang lebih 60 menit, didapatkan cairan kista sebanyak 3000 cc berwarna kecoklatan. Hemodinamik selama operasi stabil dengan tekanan darah sistolik 115$132 \mathrm{mmHg} /$ diastolik $64-78 \mathrm{mmHg}$, denyut jantung 76-82 x/menit, frekuensi nafas 14-16 
$\mathrm{x} / \mathrm{mnt}$ dengan saturasi oksigen berkisar 99-100

$\%$. Keadaan hipotensi ditangani dengan pemberian efedrin $5-10 \mathrm{mg} / \mathrm{iv}$. Selama operasi pasien diberikan sedasi dengan midazolam 2,5-5 mg. Pada saat insuflasi intra abdomen dengan gas $\mathrm{CO} 2$, dijumpai keadaan desaturasi dimana saturasi oksigen menurun hingga $90 \%$, namun dapat segera diatasi dengan pemberian oksigen. Setelah operasi berakhir pasien diberikan analgesia pronalges suppositoria sebagai analgetik pasca operatif. Selanjutnya pasien dibawa ke ruang PACU (post anesthestic care unit) dan dipantau dengan monitor. Satu jam kemudian pasien dipindahkan ke ruangan dengan Aldrette score 10. Pada hari kedua pasca operasi pasien dalam kondisi stabil dan telah diperbolehkan pulang (Eltabbakh, 2016).

\section{PEMBAHASAN}

Pada kasus di atas seorang perempuan datang ke IGD rumah sakit dengan keluhan adanya benjolan pada perut setinggi pusar. Setelah dilakukan pemeriksaan lanjutan pasien didiagnosa dengan kista ovarium permagna yang membutuhkan suatu operasi laparoskopi. Adapun teknik laparoskopi yang digunakan pada pasien ini adalah single port laparoscopy, yaitu suatu teknik laparoskopi dimana hanya membutuhkan insisi tunggal di daerah pusar. Keuntungan dari teknik ini dapat mengurangi keinvasifan tindakan (minimal invasif) dan mengurangi nyeri pasca operasi sehingga masa pemulihan menjadi lebih cepat.

Pada pemeriksaan fisik abdomen ditemukan adanya benjolan di perut setinggi pusar, pinggir rata dan bisa digerakkan pada perabaan. Pada pemeriksaan darah lengkap dan kadar gula darah sewaktu dalam batas normal. Pada pemeriksaan USG abdomen menunjukkan uterus besar biasa, tampak massa kistik, tidak terukur kaliber, massa sulit dinilai, kesimpulan kista ovarium permagna.

Pasien dipuasakan selama enam jam sebelum operasi dan dilakukan tindakan laparoskopi. Ada beberapa kekhawatiran terkait penggunaan anestesi spinal untuk prosedur laparoskopi. Insidensi hipotensi tercatat meningkat hingga $20,5 \%$ dan dapat bertambah dengan posisi
Trendelenburg dan peningkatan tekanan intra abdomen. Namun, berbagai penelitian menunjukkan bahwa hal itu dapat dengan mudah dicegah dengan memberikan preloading cairan kepada pasien, mengurangi tekanan intra abdomen dan penggunaan vasopresor.

Kejadian nyeri ujung bahu bervariasi antara 25-43\%; Mungkin akan menyusahkan pasien pada saat pasca operasi. Penyebabnya dianggap sebagai iritasi subdiapragmatika pada peritoneum oleh karena pneumoperitoneum karbon dioksida. Hal ini dapat dikurangi dengan menurunkan tekanan intra-abdomen menjadi 8$10 \mathrm{mmHg}$, pemberian anestesi lokal ke dalam rongga peritoneal atau penggunaan opioid parenteral atau dengan menggunakan propofol yang menurut beberapa penelitian efektif dalam mencegah nyeri pada bahu pasca operasi.

Perubahan mekanik pernafasan akibat pneumoperitoneum dapat menyebabkan kenaikan $\mathrm{PaCO}_{2}$ karena penyerapan dari peritoneum, yang mengakibatkan perubahan ventilasi. Namun, berbagai laporan dalam literatur mendukung perubahan yang tidak signifikan pada $\mathrm{PaO}_{2}$ atau $\mathrm{PaCO}_{2}$ selama operasi laparoskopi dengan anestesi spinal.

Bila dibandingkan dengan general anestesi teknik anestesi spinal ini memerlukan biaya yang lebih rendah sehingga dari segi ekonomi lebih menguntungkan.

\section{KESIMPULAN}

Dewasa ini tindakan laparoskopi pada pasien dengan penyakit kista ovarium sering digunakan sebagai diagnostik maupun sebagai terapi operatif untuk mengangkat massa tersebut. Prosedur laparoskopi biasanya dilakukan dengan anestesi umum karena perubahan pernafasan yang disebabkan oleh pneumoperitoneum.

Namun, penggunaan anestesi spinal telah muncul sebagai alternatif pilihan untuk laparoskopi oleh karena keamanan penggunaannya. Tetapi, anestesi spinal mungkin terkait dengan beberapa efek samping seperti kebutuhan blok sensorik yang lebih lebih tinggi, hipotensi yang lebih berat, ketidaknyamanan bahu akibat iritasi diafragma, dan gangguan 
pernafasan yang disebabkan oleh pneumoperitoneum.

Namun, hal itu dapat dicegah dengan memberikan preloading cairan kepada pasien, penggunaan vasopresor dan pemberian sedasi selama operasi sehingga pasien tetap merasa nyaman.

\section{DAFTAR PUSTAKA}

Bajwa, S. S., \& Kulshrestha, A. (2016). Anaesthesia for laparoscopic surgery: General vs regional anaesthesia. Journal of Minimal Access Surgery, 12(1), 4. https://doi.org/10.4103/0972-9941.169952

Depkes R.I. (2020). Kista Ovarium. Retrieved from http://www.medinuc.com

Eltabbakh, G. (2016). Laparoscopic surgery for large ovarian cysts-review. Curr Trends Gynecologic Oncol, 1(1), 109-111.

Hadibroto, B. R. (2005). Laparoskopi pada kista Ovarium. Majalah Kedokteran Nusantara, 38(3), 260-263.

Moradan, S. (2015). General Versus Spinal Anesthesia in Laparoscopic Ovarian Cystectomy. Zahedan Journal of Research in Medical Sciences, 17(4). https://doi.org/10.17795/zjrms974

Wiknjosastro, H. (2005). Ilmu Kandungan. Jakarta: Yayasan Bina Pustaka Sarwono Prawirohardjo. 